\title{
COMPARISON OF DYNAMIC PROPERTIES OF MAGNETORHEOLOGICAL ELASTOMERS WITH EXISTING ANTIVIBRATION RUBBERS
}

\author{
S. Raa Khimi ${ }^{1,2 *}$ and K. L. Pickering ${ }^{1}$ \\ ${ }^{1}$ School of Engineering, The University of Waikato, Hamilton, 3216, New Zealand \\ ${ }^{2}$ School of Materials and Mineral Resources Engineering, USM Engineering Campus, Universiti \\ Sains Malaysia, 14300 Nibong Tebal, Penang, Malaysia \\ *Corresponding author: Tel: +64 078384672; email address: raa_khimi@hotmail.com
}

\begin{abstract}
Tan $\delta$ and energy dissipated during hysteresis testing of isotropic and anisotropic MREs containing silane modified iron sand particles in a natural rubber matrix were compared with existing antivibration rubbers. Tan $\delta$ was measured using dynamic mechanical analysis (DMA) over a range of frequency $(0.01-130 \mathrm{~Hz})$, strain amplitude $(0.1-4.5 \%)$, and temperature $\left(-100-50^{\circ} \mathrm{C}\right)$. Energy dissipated was measured using a universal tester under cyclic tensile loading. The chosen antivibration rubbers for comparison contained different contents of carbon black filler (30, 50 and $70 \mathrm{phr}$ ) in a natural rubber matrix. It was found that energy absorption for comparative samples was generally higher than isotropic and anisotropic MREs over the range of frequency and strain amplitude explored, as well as in hysteresis testing and this was believed to be largely due the presence of carbon black in the formulation. Further assessment was carried out on materials that were the same as anisotropic MREs except they had additions of carbon black. The energy absorption was found higher than comparative samples with the same carbon black contents, supporting the use of iron sand to improve damping. However, trends for energy absorption at around $\mathrm{T}_{\mathrm{g}}$ were found to reverse which is considered to be due to the segmental motion of rubber chains being by far the most significant influence on energy absorption in the glass transition zone.
\end{abstract}

Keywords: A. Particle-reinforcement; B. Vibration; D. Mechanical testing 


\subsection{INTRODUCTION}

Magnetorheological elastomers (MREs) are a new group of damping materials which consist of a non-magnetic matrix (normally an elastomer) containing a suspension of magnetically permeable particles. Damping occurs by the viscous flow of the rubber matrix and inclusion of magnetic particles in rubber enables additional damping through magnetic particle interaction and interfacial damping. The magnetic particles of choice are carbonyl iron, magnetite, iron oxides, barium ferrite or TerfenolD [1-3] and suitable matrix materials include natural rubber, silicone rubber, polybutadiene, polyisobutylene, polyisoprene and polyurethene rubber [4-11]. The main advantage of MREs is that the damping and stiffness can be varied by application of an applied magnetic field during fabrication or in service. MREs can be classified into two kinds: isotropic MREs and anisotropic MREs [12]. Figure 1 shows structure of isotropic and anisotropic MREs. Isotropic MREs can be characterized by having a uniform magnetic particle distribution in the matrix. Anisotropic MREs have a special chainlike structure of magnetic particles in a matrix resulting from curing the matrix under an applied magnetic field. Over the past few years, MREs have attracted increasing attention and have been considered for applications such as adaptive tuned vibration absorbers [13], automotive engine mounts [8] and semi active seismic dampers [14].
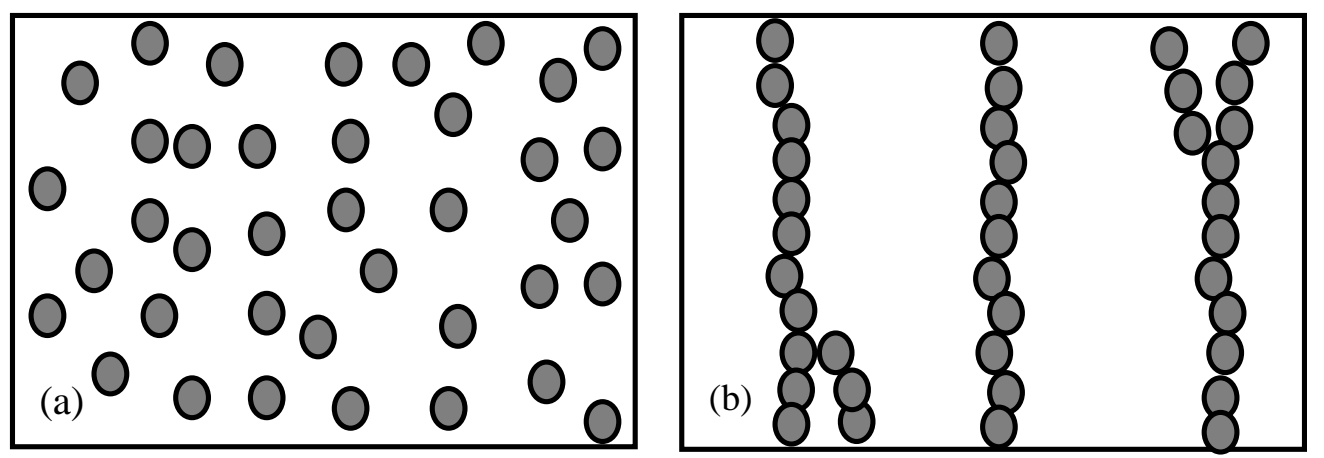

Figure 1 MRE structure: (a) isotropic MRE; and (b) anisotropic MRE. 
In this study, isotropic and anisotropic MREs based on natural rubber and silane modified iron sand particles were prepared. The natural rubber was used as a matrix because of its associated ease of processing and good damping performance [14-16] and iron sand was chosen as magnetic particles because it has high permeability and saturation magnetisation, low cost and is readily available in New Zealand. Surface modification of iron sand using silane coupling agent was found to provide coupling between iron sand and natural rubber [15]. It has also been reported that the silane modified particles decrease the interfacial tension around the particles and results in improved dispersion of magnetic particles in isotropic MREs and an improved degree of magnetic particle alignment in anisotropic MREs [16, 17].

This work aims to assess the potential of developed MREs for potential use in vibration damping. The dynamic properties of isotropic and anisotropic MREs were compared with existing antivibration rubbers. The dynamic properties were investigated using two different methods. The loss tangent, commonly called $\tan \delta$, is considered as the fundamental parameter to assess damping. Tan $\delta$ gives a comparison of the energy lost to that stored; it is obtained by dividing the loss modulus $\left(\mathrm{G}^{\prime \prime}\right.$ or $\left.\mathrm{E}^{\prime \prime}\right)$ by the storage modulus $\left(\mathrm{G}^{\prime}\right.$ or $\left.\mathrm{E}^{\prime}\right)[12,18]$. The other estimate of damping used was the amount of energy dissipated during cyclic deformation, which can be calculated from the area of the hysteresis loop. The antivibration rubbers for comparison were prepared according to existing formulations from published patents (see details in Table 1). Those chosen, contained different contents of carbon black filler (30, 50 and $70 \mathrm{phr}$ ) in a natural rubber matrix. In addition, anisotropic MREs containing silane modified iron sand and a predetermined amount of carbon black were also prepared in order to investigate the influence of carbon black on the damping performance of the MREs. 
Table 1 Comparative samples’ patent specifications

\begin{tabular}{|c|c|c|c|c|}
\hline $\begin{array}{c}\text { Comparative } \\
\text { sample }\end{array}$ & $\begin{array}{c}\text { Patent } \\
\text { number }\end{array}$ & Applicant & Title & Description \\
\hline 1 & $\begin{array}{l}\text { US } \\
\text { 2011/016627 } \\
\text { 6 A1 [18] }\end{array}$ & $\begin{array}{l}\text { Tokai Rubber } \\
\text { Industries Ltd }\end{array}$ & $\begin{array}{l}\text { Antivibration } \\
\text { rubber composition }\end{array}$ & $\begin{array}{l}\text { The invention relates to a vibration } \\
\text { damping rubber composition to be } \\
\text { used for an engine mount or the like } \\
\text { adapted to support an engine in an } \\
\text { automobile or the like and suppress } \\
\text { transmission of vibrations. }\end{array}$ \\
\hline 2 & $\begin{array}{l}\text { EP } 0481810 \\
\text { B1 [19] }\end{array}$ & $\begin{array}{l}\text { Sumitomo } \\
\text { Rubber } \\
\text { Industries Ltd }\end{array}$ & $\begin{array}{l}\text { Rubber } \\
\text { composition for } \\
\text { laminated vibration } \\
\text { proofing structure }\end{array}$ & $\begin{array}{l}\text { The present invention relates to a } \\
\text { rubber composition for use in the } \\
\text { seismic isolation of a bridge, a } \\
\text { building or a house. }\end{array}$ \\
\hline 3 & $\begin{array}{l}\text { US6180711 } \\
\text { B1 [20] }\end{array}$ & $\begin{array}{l}\text { Yokohama } \\
\text { Rubber Co. } \\
\text { Ltd }\end{array}$ & $\begin{array}{l}\text { Rubber } \\
\text { composition for } \\
\text { seismic isolation } \\
\text { laminates }\end{array}$ & $\begin{array}{l}\text { This invention relates to a rubber } \\
\text { composition for seismic isolation } \\
\text { laminate for buildings. }\end{array}$ \\
\hline
\end{tabular}

\subsection{EXPERIMENTAL}

\subsection{Materials}

Natural rubber (SMR L grade) and other chemicals including zinc oxide, stearic acid, ncyclohexyl-2-benzothiazole sulfenamide (CBS), tetramethylthiuram disulphide (TMTD), paraffin oil, and naphthenic oil were all purchased from Field Rubber Limited, Auckland. Bis-(3triethoxysilylpropyl) tetrasulphane (TESPT) was purchased from Leap Lab Chem Co. Ltd. Carbon black was purchased from Shijiazhuang Changhang Co. Ltd. Iron sand was collected from Ngarunui Beach, Raglan. The iron sand was then milled using a planetary mono mill (Pulverisette 6) produced by Fristech GmbH and subsequently sieved to obtain a $45-56 \mu \mathrm{m}$ particle size range.

\subsection{Surface Modification of Iron Sand}

The surface modification of iron sand was carried out using an aqueous alcohol solution method. Iron sand particles were subjected to surface treatment with TESPT at $6 \mathrm{wt} \%$ relative to the 
weight of the particles. An aqueous alcohol solution of 95 vol\% ethanol was used and the $\mathrm{pH}$ of the solution was adjusted with acetic acid to 4.0 - 4.5. TESPT of predetermined quantity was dispersed in the ethanol solution at a ratio of 1:100 and the mixed solution was stirred for 5 minutes to ensure hydrolization of the silane coupling agent. The iron sand particles were then added and stirred for an additional 30 minutes at room temperature to ensure a uniform distribution of the coupling agent on the surface of iron sand particles. The mixture was filtered and washed three times with ethanol to remove unreacted coupling agent. The treated iron sand particles were then dried at $80^{\circ} \mathrm{C}$ in an oven until a constant weight was achieved.

\subsection{Preparation of MREs and comparative samples}

The compound formulation used in this study is given in Table 2. The formulations of comparative samples based on published patents comprised of natural rubber and carbon black as the major components with processing aids and crosslinking agent. Additives such as anti antioxidant, anti-thermal aging agent and petroleum resin were excluded from the formulations. Formulations were compounded using a conventional laboratory two roll mill (model XK150) according to ASTM designation D3184-80. The front roller speed was $24 \mathrm{rpm}$ and the rear roller speed was $33 \mathrm{rpm}$, the roller diameters were $150 \mathrm{~mm}$, friction ratio of two rollers was 1:1.4 and the roller temperature was set to $80^{\circ} \mathrm{C}$. The nip gap (distance between front and back roller) was maintained at $2 \mathrm{~mm}$ during compounding. The compounding began with softening the rubber on its own in the two roll mill (mastication). Mastication reduces the viscosity and increases the plasticity of natural rubber by mean of heat generated in the two roll mill through conduction from the heated roller and shearing of rubber during milling. After 2-3 minutes the rubber became invested on the hot roll and additives (other than accelerators and sulphur) were then added followed by filler (iron sand or carbon black); addition of accelerators and sulphur were delayed to the last part of the process to prevent premature vulcanization during compounding. The mixing time was approximately 40 minutes. The cure time at $150^{\circ} \mathrm{C}$ was then determined according to the procedure as described elsewhere [19]. Compounded rubber samples weighing $13 \mathrm{~g}$ were placed in a mould $60 \times 50 \times 3 \mathrm{~mm}$. The isotropic MREs and 
comparative samples were cured in a compression moulder at $150^{\circ} \mathrm{C}$ under a pressure of approximately $12 \mathrm{MPa}$. The anisotropic MREs were subjected to an external magnetic field in a specially developed electromagnetic-thermal coupled device (as shown in Figure 2) at $80^{\circ} \mathrm{C}$ for 30 minutes and subsequently were cured in a compression moulder at $150^{\circ} \mathrm{C}$ under a pressure of approximately 12 MPa. Finally, post-cure treatment was performed by cooling the anisotropic MREs at room temperature for 30 minutes under an external magnetic field of the same strength as that used during pre-curing. The post-cure treatment was considered necessary to reorientate the magnetic dipoles after compression moulding. 
Table 2 Formulation of rubber compounds

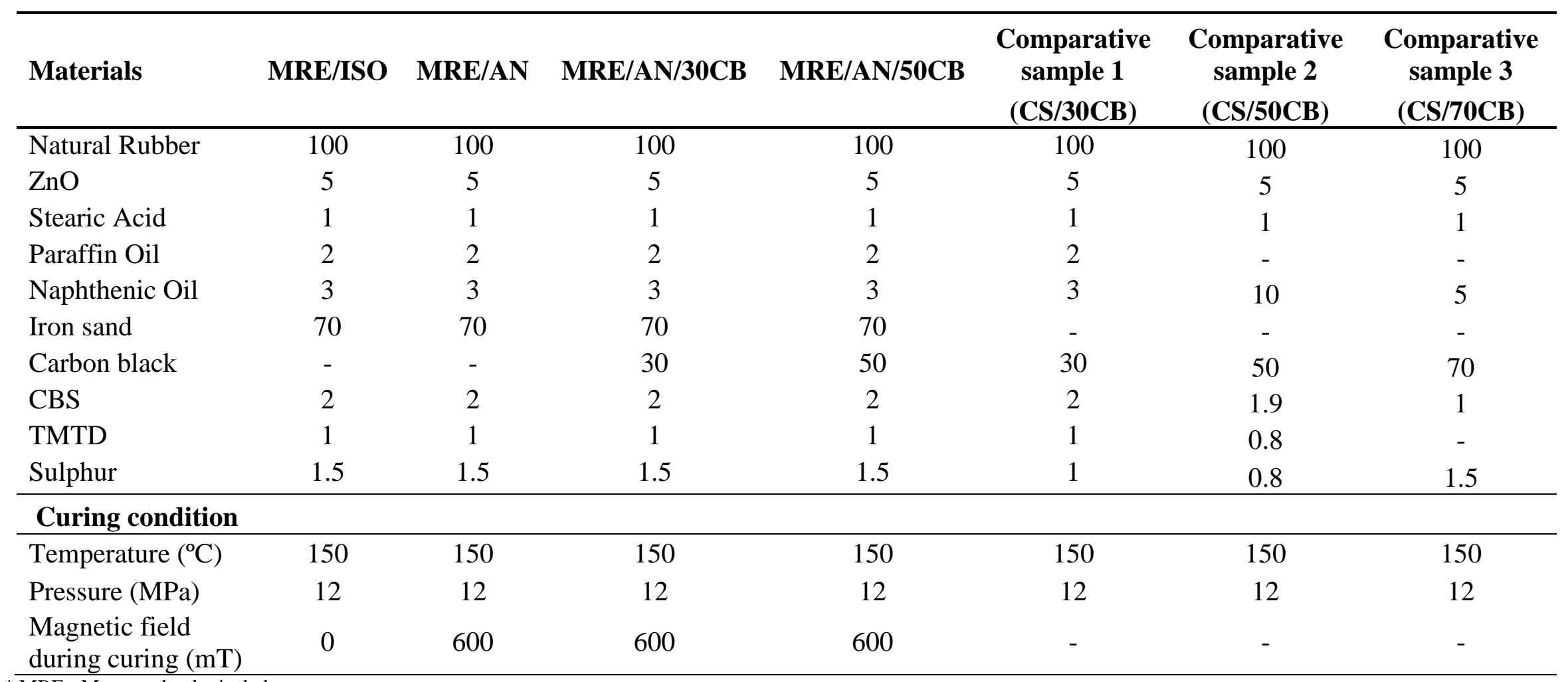

* MRE= Magnetorheological elastomers

* ISO= Isotropic

* AN= Anisotropic

* CB= Carbon Black

* CS= Comparative sample 


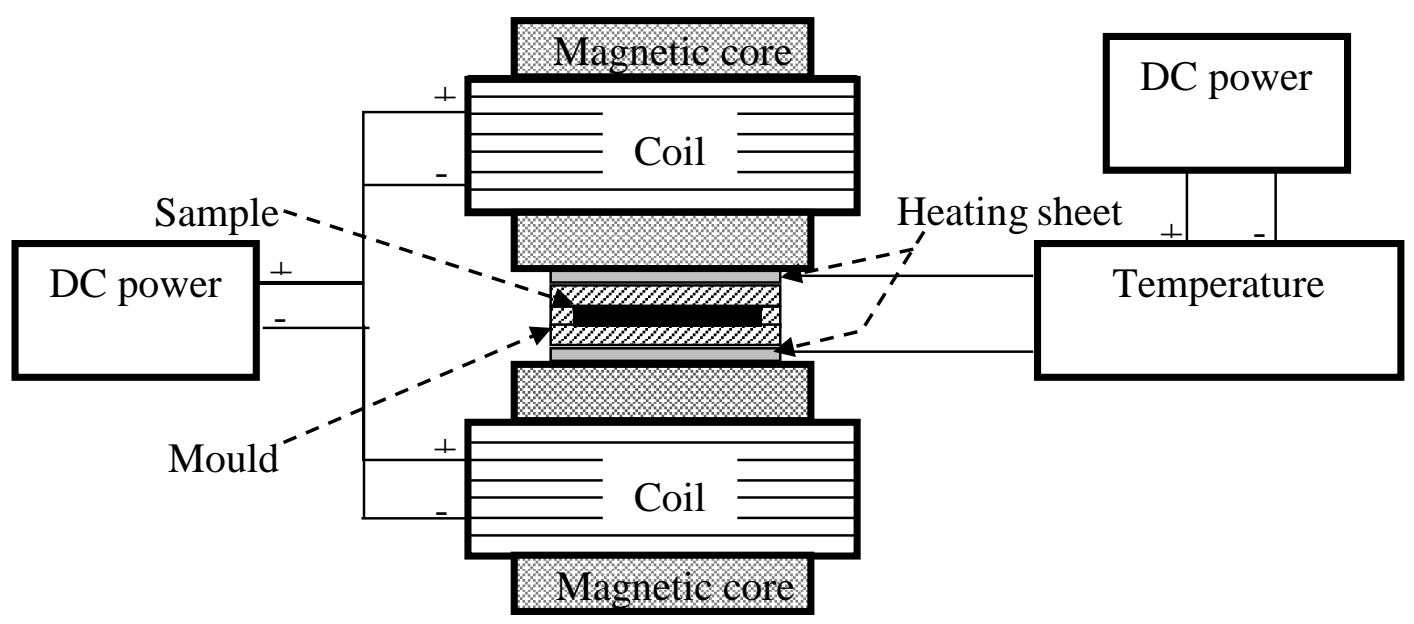

Figure 2 Sketch of specially developed electromagnetic-heat coupled device.

\subsection{Dynamic mechanical analysis}

Dynamic mechanical analysis (DMA) is a technique used to measure damping of materials as they are deformed under periodic force. In DMA, a sinusoidal force at different frequencies, strain amplitudes and temperatures is applied and displacement of the materials is measured, allowing one to determine the storage modulus ( $\mathrm{G}^{\prime}$ or $\left.\mathrm{E}^{\prime}\right)$, loss modulus $\left(\mathrm{G}^{\prime \prime}\right.$ or $\left.\mathrm{E}^{\prime \prime}\right)$ and $\tan \delta$. DMA was carried out using a Perkin Elmer dynamic mechanical analyser (DMA 8000). It is made up of six major components (Figure 3): a force motor, a drive shaft, a high sensitivity displacement detector (LVDT), a sample fixture, a furnace and a temperature controller. The driveshaft motion was kept in a horizontal direction during the test and the temperature controller was placed at a minimum distance from the sample. Tan $\delta$ was measured over a wide range of frequency, strain amplitude and temperature. The influence of frequency and strain amplitude on $\tan \delta$ was assessed using two circular disc specimens with a diameter of $10 \mathrm{~mm}$ and a thickness of $3 \mathrm{~mm}$ in shear mode at room temperature. Tan $\delta$ was measured over the frequency range of $0.01-130 \mathrm{~Hz}$ at a fixed strain amplitude of $0.5 \%$ and over a strain amplitude range of $0.1-4.5 \%$ at a fixed frequency of $100 \mathrm{~Hz}$. For the influence of 
temperature on $\tan \delta$, the samples were analysed in dual cantilever mode at a frequency of $1 \mathrm{~Hz}$ with a strain amplitude of $0.5 \%$ and over a temperature range from $-100-50{ }^{\circ} \mathrm{C}$. The samples were rectangular with dimensions $30 \mathrm{~mm} \times 6 \mathrm{~mm} \times 3 \mathrm{~mm}$.

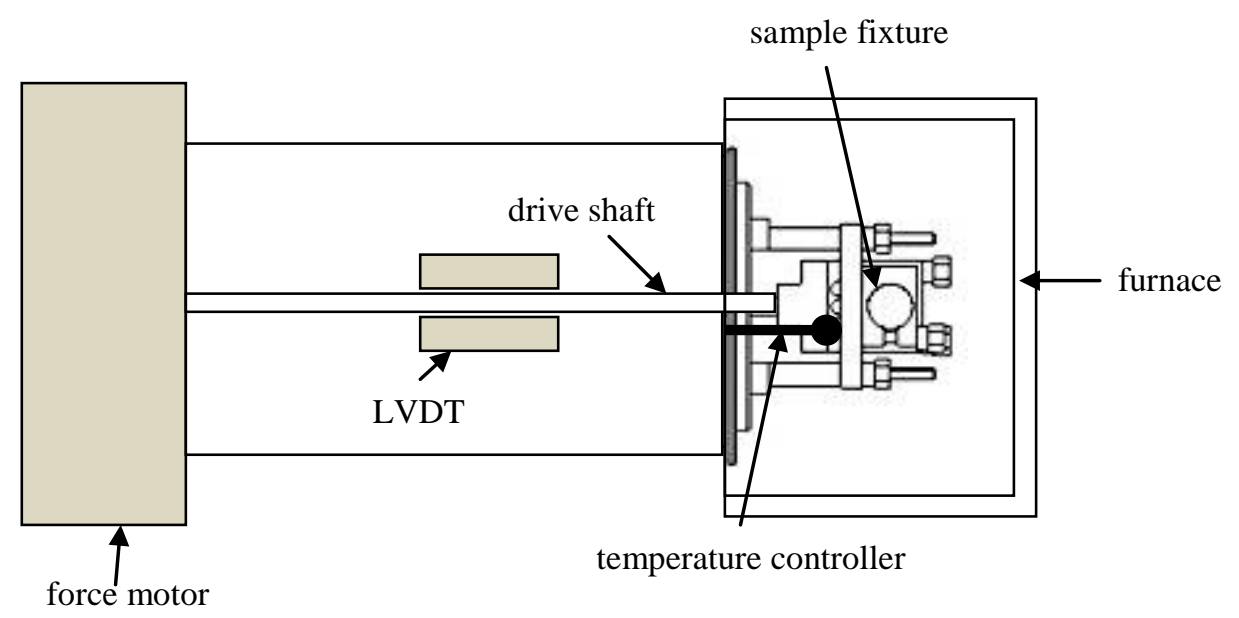

Figure 3 Scheme of the DMA 8000

\subsection{Hysteresis}

Hysteresis loss is defined as the amount of energy dissipated during cyclic deformation when the samples are stretched and then allowed to retract at the same rate to the unstretched state. In this study, the hysteresis loss was determined for tensile dumbbells using an Instron 4204 at a crosshead speed of 500mm/min according to ASTM D412-80. The stress-strain curve was recorded and hysteresis loss was calculated as:

Hysteresis loss = Area under the loading curve - Area under the recovery curve

\subsection{Morphology}


The microstructures of isotropic and anisotropic MREs were observed using a Hitachi S-4700 scanning electron microscope (SEM). The samples were cut into pieces with a surface area of $5 \mathrm{~mm}$ $\times 3 \mathrm{~mm}$ and coated with a thin layer of platinum prior to observation at an accelerating voltage of $20 \mathrm{kV}$.

\subsection{RESULTS AND DISCUSSION}

\subsection{Morphology}

Figure 4 shows SEM images of MREs and comparative samples. It can be seen that MRE/ISO had uniform iron sand particle distribution in the rubber matrix without obvious aggregation (Figure 4a). Figure 4b shows an MRE/AN sample cured under an applied magnetic field of $600 \mathrm{mT}$ at elevated temperature; as expected, the iron sand organized into chain-like columnar structures. For comparative samples, the carbon black particles were generally evenly distributed in the rubber matrix but with some aggregates ranged probably from below the resolution of the SEM up to $20 \mu \mathrm{m}$ as seen in Figure 4c. It can be seen that the distribution of carbon black in the rubber matrix has occurred similarly to that obtained elsewhere [20]. For MRE/AN/50CB sample (Figure 4d), it can be seen that the presence of carbon black has constrained the movement of iron sand particles and the chain-like columnar structures are shorter and less aligned than MRE/AN sample. 

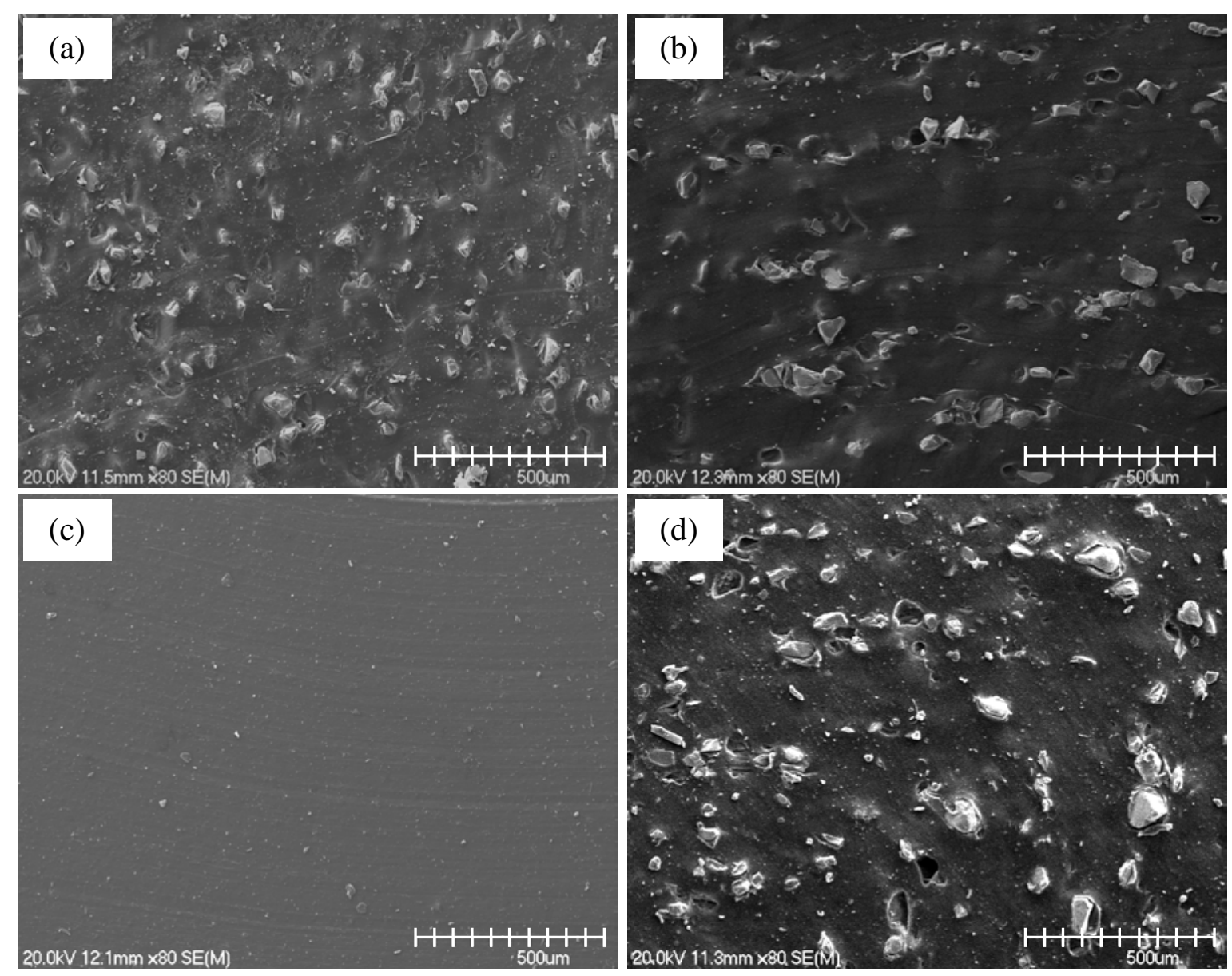

Figure 4 SEM images of surface of; (a) MRE/ISO (ISO), (b) MRE/AN, (c) CS/50CB and

(d) MRE/AN/50CB at x80 magnitude of enlargement.

\subsection{Dynamic Mechanical Analysis}

\subsubsection{Frequency Sweep Measurements}

The variation of $\tan \delta$ with frequency for MREs and comparative samples is depicted in Figure 5a. Generally, $\tan \delta$ increased with increasing frequency, with $\tan \delta$ values for both MRE/ISO and MRE/AN found to be lower than for the others at most frequencies, although relatively larger increases in $\tan \delta$ above $100 \mathrm{~Hz}$ compared to other samples occurred, such that at the highest frequencies explored, $\tan \delta$ values for MRE/ISO and MRE/AN were at the upper end of those 
obtained. The increase of $\tan \delta$ as the frequency increased for isotropic MREs and comparative samples could be due to increased energy absorbed through viscous flow of the rubber matrix and interfacial damping between the particle and the rubber matrix [15]; for anisotropic MREs similar mechanisms would be involved as well as potentially, energy absorbed through magnetic interactions [21]; for samples containing carbon black, increased energy could be absorbed due to overcoming inter-particle interactions (Van der Waals) [22]. The difference in trends observed for MREs and comparative samples are likely to be due to the relatively different amounts of energy absorbed by different mechanisms involved with different reinforcement particles at different frequencies.
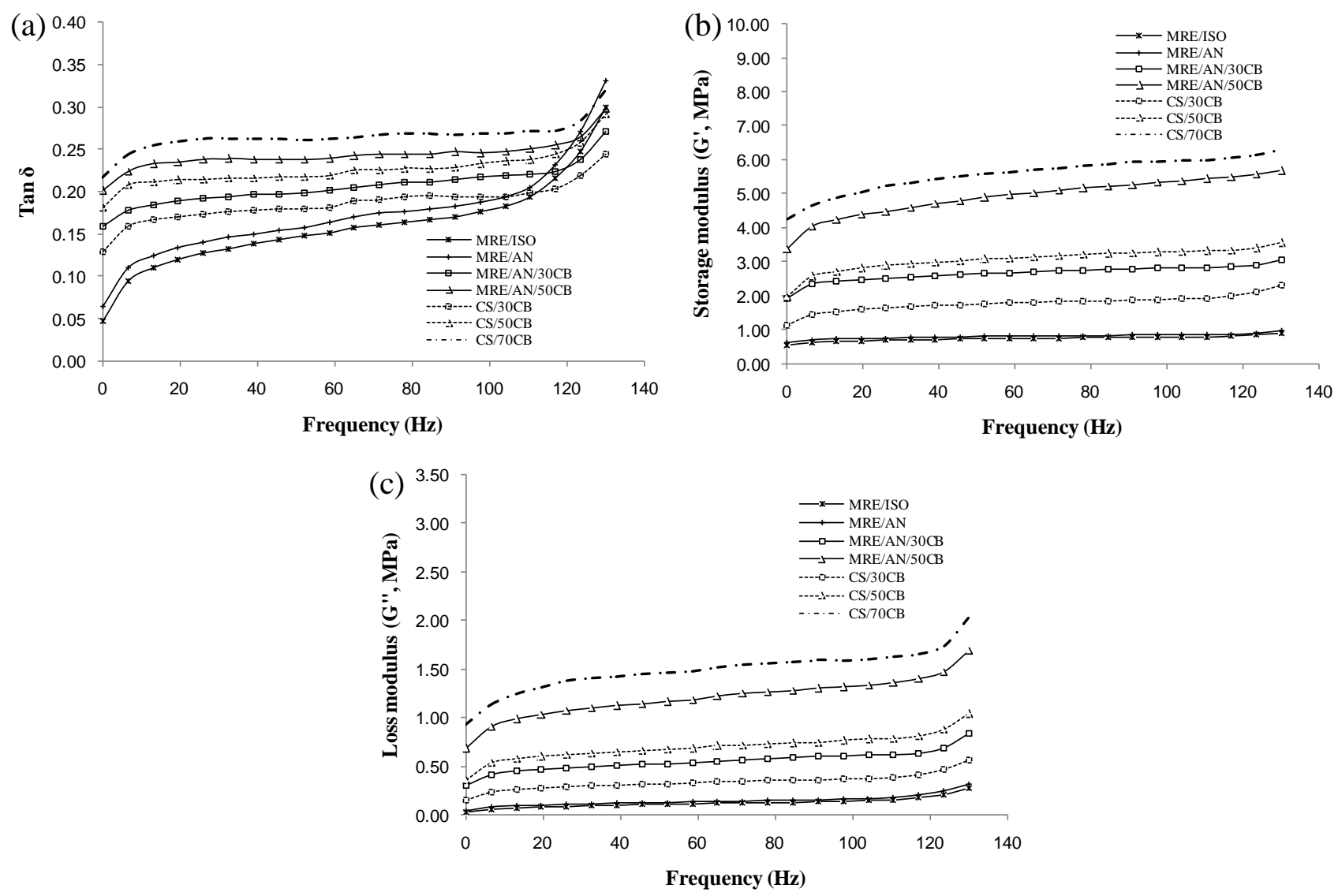

Figure 5 (a) Tan $\delta$, (b) storage modulus $\left(G^{\prime}\right)$ and loss modulus $\left(G^{\prime \prime}\right)$ versus frequency for MREs and comparative samples. 
It can also be seen that $\tan \delta$ of MRE/AN is about $8 \%$ higher than MRE/ISO over the whole frequency range explored; the higher $\tan \delta$ of MRE/AN can be attributed to multiple mechanisms such that include constraint of joint rubber shells between neighbouring iron sand particles, less trapped rubber due to formation of aligned structures and damping through inter-particle magnetic interactions as well as magnetomechanical effect (change of magnetic domain structure induced by application of stress) [21, 22]. For the comparative samples, $\tan \delta$ increased in the following order: $\mathrm{CS} / 30 \mathrm{CB}<\mathrm{CS} / 50 \mathrm{CB}<\mathrm{CS70/CB}$, correlating with the increased content of carbon black. A significant improvement of $\tan \delta$ was observed for comparative samples when compared to MRE/ISO and MRE/AN; it was suspected that this could be due to the presence of carbon black in the formulation. In order to assess the influence of carbon black on damping performance of MREs, two compounds were prepared that were the same as MRE/AN except they had additions of 30 and 50 phr carbon black (MRE/AN/30CB and MRE/AN/50CB). It was found that such additions of carbon black gave good improvement of $\tan \delta$, the $\tan \delta$ values for MRE/AN/30CB and MRE/AN/50CB were $21 \%$ and $43 \%$ higher than MRE/AN, indeed, the tan $\delta$ were $10 \%$ and $7 \%$ higher compared to CS/30CB and CS/50CB over the whole frequency range explored; supporting the use of iron sand to improve damping through interfacial damping between the particle and the rubber matrix and magnetic interactions (magnetomechanical and inter-particle interaction).

The effect of carbon black on tan $\delta$ can be analysed further using storage modulus $\left(\mathrm{G}^{\prime}\right)$ and loss modulus (G") plots as shown in Figure 5 (b and c). It is apparent that $G^{\prime}$ and $G^{\prime \prime}$ for samples containing carbon black are much higher than those for MRE/ISO and MRE/AN. The G' increases with increasing carbon black content up to the highest values at 70 phr carbon black. The increase in G' can be explained by increased carbon black particle-rubber interactions and carbon black particleparticle interactions as reported by number of researchers [22, 23]. The particle-rubber interactions include physical adsorption of rubber chains on carbon black filler surfaces and chemical bonding between functional groups on the surface of carbon black (mostly quinonic groups) with rubber 
molecular chains which will restrain the mobility of rubber on the filler surface [24]. The particleparticle interactions relate to the tendency of carbon black particles to form aggregates at different levels [24]. Carbon black aggregates agglomerate together to form what are known as primary aggregates, held together by Van der Waals bonds. Further agglomeration occurs between primary aggregates to produce secondary aggregates, again held together by Van der Waals bonds, although the secondary aggregates are less rigidly held together. The particle-rubber interactions and particleparticle interactions lead to the formation of a carbon black filler networks in the rubber matrix as shown in Figure 6. These contain rubber with different degrees of constraint (bound rubber, occluded rubber and trapped rubber), higher than that for rubber away from carbon black particles [25]. These constrained rubber regions improve the ability to store elastic energy, resulting in increased G'. The increase of G" with increasing carbon black content during deformation can be explained by the increased energy loss that occurs due to the breakdown and reformation of the carbon black filler networks.

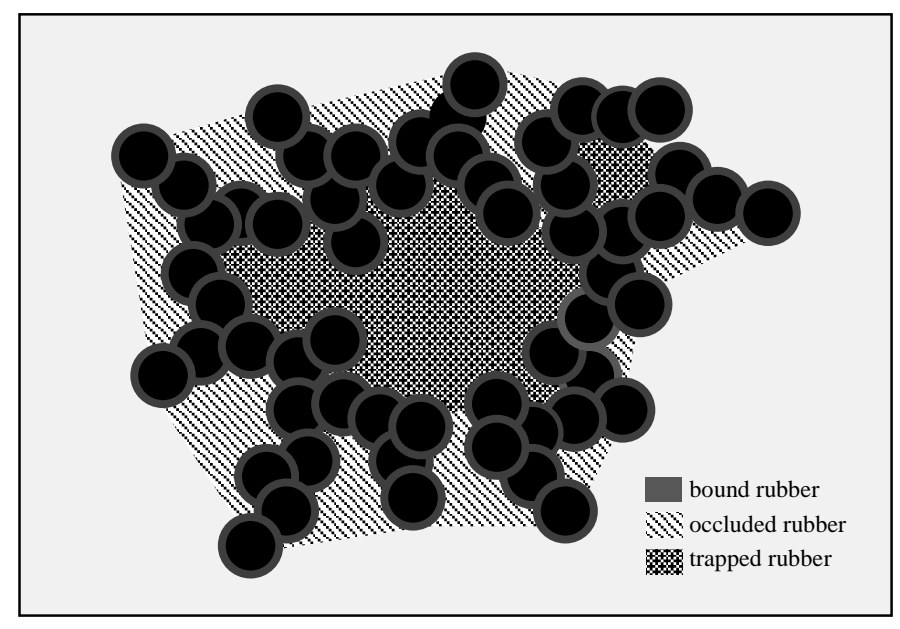

Figure 6 Schematic presentation of carbon black filler network.

\subsubsection{Strain Amplitude Sweep Measurements}


The variation of $\tan \delta$ with strain amplitude for MREs and comparative samples is depicted in Figure 7a. Tan $\delta$ was amplitude dependent at low strain amplitude before reaching a plateau, with increasing $\tan \delta$ for MRE/AN and MRE/ISO at around 2.5\% strain amplitude, whereas for the other samples containing carbon black the $\tan \delta$ reached a plateau at around $1.5 \%$ strain amplitude. The increased amplitude dependence for MRE/AN and MRE/ISO compared to comparative samples indicates that the amplitude of applied strain required to break stronger interfacial bonding between iron sand and rubber was relatively larger compared to easier that required for breaking down carbon black filler networks. At the plateau region, it would appear that most of the filler-rubber interactions diminish (Van der Waals for carbon black and Van der Waals and covalent for iron sand) and tan $\delta$ is largely reliant on the rubber matrix which is at its largest due to greatest amount of rubber free to flow and friction between rubber chains and iron sand [15, 26]. 

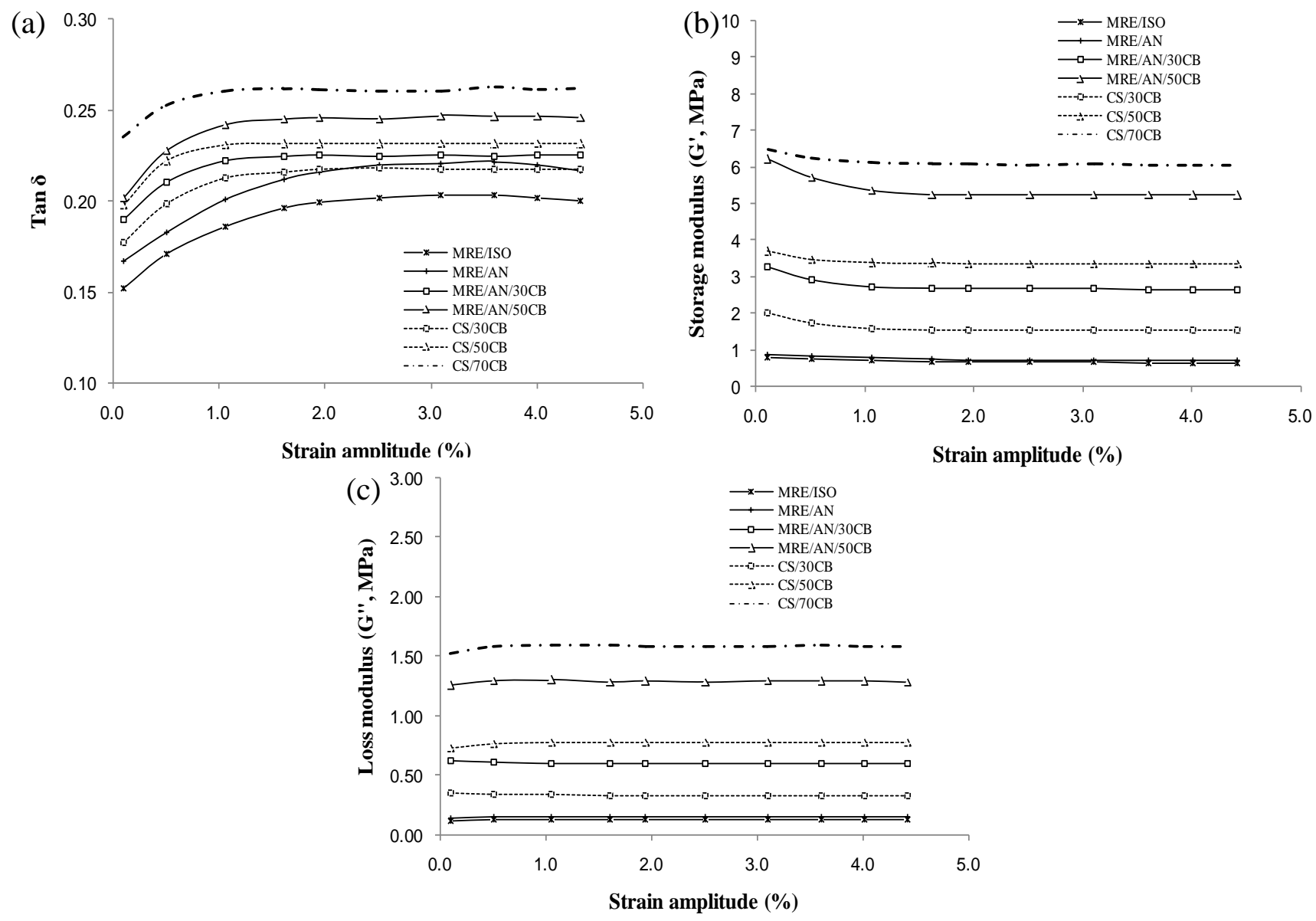

Figure 7(a) Tan $\delta$, (b) storage modulus $\left(G^{\prime}\right)$ and loss modulus $\left(G^{\prime \prime}\right)$ versus strain amplitude for MREs and comparative samples.

Tan $\delta$ of MRE/AN was found to be $8.5 \%$ higher than that of MRE/ISO over the whole strain amplitude range explored; the higher $\tan \delta$ for MRE/AN can again be explained due to additional damping through breakdown of joint rubber shells, more trapped rubber released and magnetic interactions (magnetomechanical and inter-particle interaction). Indeed, it can also be seen that although the $\tan \delta$ for MRE/AN is lower at low strain amplitudes, it is slightly higher than for $\mathrm{CS} / 30 \mathrm{CB}$ above a strain amplitude of $2 \%$. For the comparative samples, $\tan \delta$ increased in the 
following order: CS/30CB < CS/50CB < CS70/CB, along with the increased content of carbon black. Similarly, $\tan \delta$ values for MRE/AN/30CB and MRE/AN/50CB were higher than MRE/AN (6\% and $15 \%$, respectively) and the $\tan \delta$ approximately $4 \%$ and $5 \%$ higher compared to $\mathrm{CS} / 30 \mathrm{CB}$ and CS/50CB over the strain amplitude range explored as was seen for range of frequency discussed in the previous section.

Again, the effect of carbon black on improved $\tan \delta$ can be analysed further using $\mathrm{G}^{\prime}$ and $\mathrm{G}^{\prime \prime}$ plots as shown in Figure 7 (b and c). It is apparent that $\mathrm{G}^{\prime}$ and $\mathrm{G}$ " for samples containing carbon black are much higher than MRE/ISO and MRE/AN, which is not surprising given similar trends with influence of frequency on G' and G". As previously discussed, the increase of G' with increase in carbon black content can be explained by increased amount of constrained rubber in filler networks and the increased energy loss is likely due to breakdown and reformation of filler networks during cyclic deformation along with more constrained rubber flow.

\subsubsection{Temperature Sweep Measurements}

Figure 8 presents the tan $\delta$ versus temperature curves for MREs and comparative samples. The $\tan \delta$ peak is associated with the glass transition temperature $\left(\mathrm{T}_{\mathrm{g}}\right)$ of the materials. In general, the trend for the height of the $\tan \delta$ peak is different compared to trends observed previously for the effect of frequency and strain amplitude on $\tan \delta$; the $\tan \delta$ peaks for MRE/ISO and MRE/AN are higher than for the others and the height of the $\tan \delta$ peak decreased with increasing carbon black content in

the following order: CS/30CB > CS/50CB > CS70/CB. To explain the trend seen here, it is necessary to consider the relative change of contributions by different energy dissipation mechanisms in the glass transition zone. It is known for materials containing non-magnetic particles, that in the glass transition zone, contribution from segmental motion of rubber chains generally far outweighs that through breakdown of filler-filler and filler-rubber interactions [27]; furthermore for anisotropic MREs, the damping through magnetic interactions around $\mathrm{T}_{\mathrm{g}}$ is thought to be insignificant compared with that due to segmental motion of rubber chains with the height of the $\tan \delta$ peak for anisotropic 
MREs having been observed to be lower than unfilled natural rubber [28]. Based on such importance of rubber chain motion, the higher tan $\delta$ peak for MRE/ISO and MRE/AN can be explained due to a greater volume of free rubber chains participating in large scale motions at $T_{g}$ which is likely to be due to less constrained rubber with iron sand particles in the MRE/ISO and MRE/AN than with carbon black particles in the MREs containing carbon black and comparatives samples due to the difference in interfacial area, being much smaller in the case of the much larger iron sand particles. For samples containing carbon black, further regions of constrained rubber would also form within carbon black filler networks; this constrained rubber is shielded from deformation and loses its ability to participate in the energy dissipation process. There also appears to be a slightly higher $\tan \delta$ peak for MRE/AN compared with MRE/ISO which is likely to be due to formation of aligned structures in anisotropic MREs reducing the amount of trapped rubber. The decrease in height of the $\tan \delta$ peak with increased carbon black content could be explained by the increased amount of constrained rubber on carbon black surfaces and within filler networks. The height of the tan $\delta$ peaks for MRE/AN/30CB and $\mathrm{MRE} / \mathrm{AN} / 50 \mathrm{CB}$ were found to be lower than the tan $\delta$ peaks for $\mathrm{CS} / 30 \mathrm{CB}$ and $\mathrm{CS} / 50 \mathrm{CB}$, supporting iron sand contributing to rubber constraint. It is also apparent that $T_{g}$ values for MRE/ISO and MRE/AN are the highest followed by MRE/AN/30CB and MRE/AN/50CB and comparative samples. This observation suggests that strong interfacial bonding between iron sand and rubber increased the temperature required for the rubber molecular chains to attain maximum segmental motion compared to weak Van der Wall bonds in samples containing carbon black. 


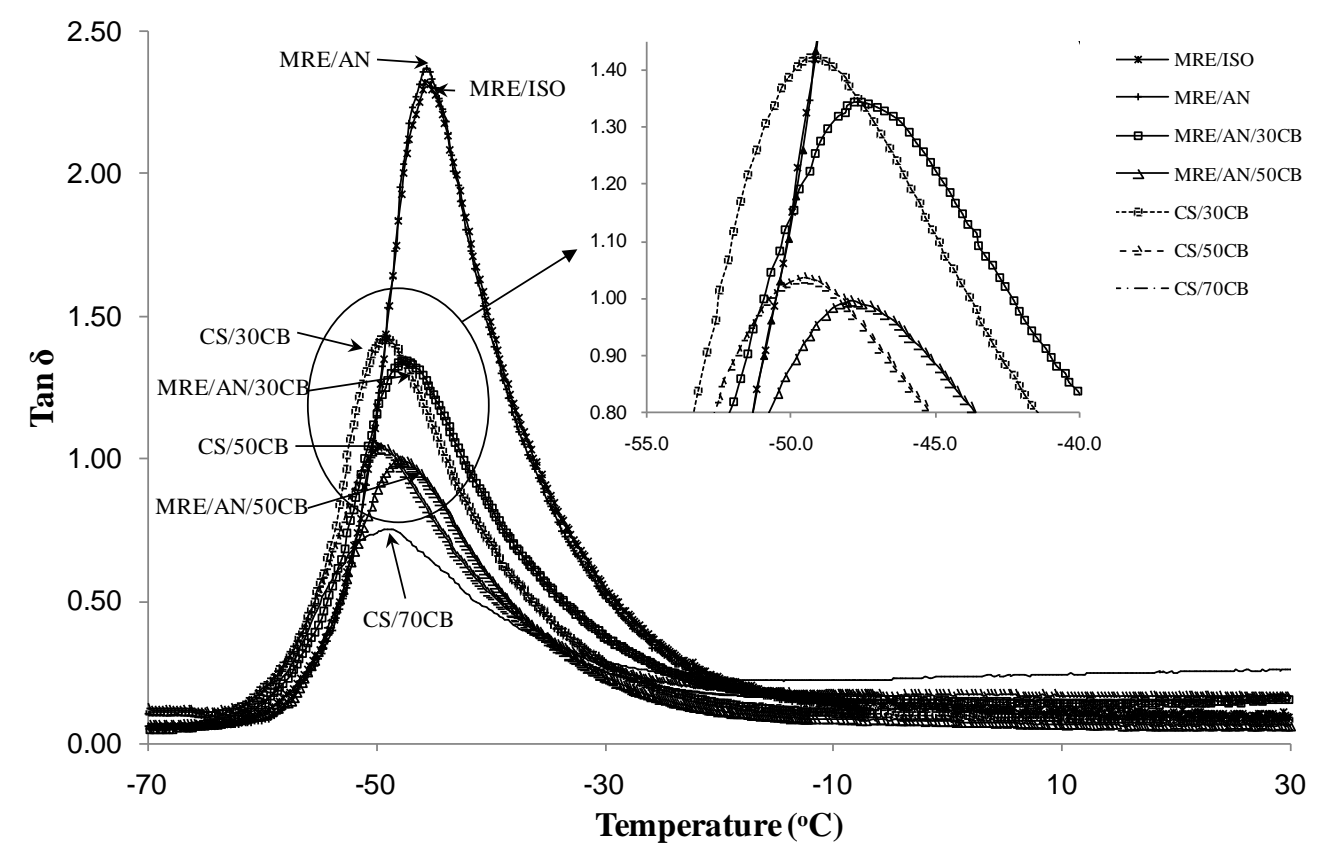

Figure 8 Tan $\delta$ versus temperature curves for MREs and comparative samples.

\subsubsection{Hysteresis}

Figure 9 shows hysteresis loss for MREs and comparative samples. Hysteresis loss for both MRE/ISO and MRE/AN was found to be lower than for the other samples. Hysteresis loss in isotropic MREs could be associated with the energy absorbed during viscous flow which is constrained due to strong interfacial bonding between iron sand and rubber and energy loss due to stress released in breaking the interfacial bonding [15] and given higher hysteresis loss than for unfilled rubber (31 $\mathrm{kJ} / \mathrm{m}^{3}$, as obtained elsewhere [28]) ; for anisotropic MREs similar mechanisms would be involved as well as energy loss due to breakdown of joint rubber shells with more trapped rubber released, however, the damping through magnetic interactions would appear to be insignificant given that the hysteresis loss for MRE/AN was lower than MRE/ISO. This seems to contradict the results for the effect of frequency and strain amplitude on $\tan \delta$, which could be explained as being due to a different mode of loading as shown in Figure 10 (tensile versus shear). In tension as in the case here, it is 
largely the spacing increasing between chains that is changing, whereas in shear loading, the spacing within chains and so between the particle increases [28]. It is possible that in the direction of tensile loading, the particles are separated to such an extent in anisotropic MREs that inter-particle attraction is less effective than for the isotropic MREs.

For the comparative samples, hysteresis loss increased in the following order: CS/30CB < CS/50CB < CS70/CB, along with the increased content of carbon black. This could be explained due to increased energy absorbed caused by breakdown and reformation of carbon black filler networks with increase in carbon black content which becomes more significant than the reduction of segmental motion of rubber chains (away from $\mathrm{T}_{\mathrm{g}}$ ). Furthermore, when the applied strain increases to such an extent the filler network can be broken down, the constrained rubber would be released and therefore allow more viscous flow during deformation, resulting in an increase of dissipated energy [29, 30]. As can also be seen, hysteresis loss for MRE/AN/30CB and MRE/AN/50CB significantly increased compared to MRE/AN (21\% and 71\%, respectively), supporting the data obtained for assessment of the effect of frequency and strain amplitude on $\tan \delta$, that addition of carbon black results in higher energy dissipation in the materials (other than around $\mathrm{T}_{\mathrm{g}}$ ). Also hysteresis losses for MRE/AN/30CB and MRE/AN/50CB were approximately 5\% and 8\% higher compared to CS/30CB and CS/50CB, supporting the use of iron sand to improve hysteresis loss through interfacial damping between the particle and the rubber matrix (constraint of viscous flow due to strong interfacial bonding between iron sand and rubber, energy loss due to breakdown of the interfacial bonding and breakdown of joint rubber shells with more trapped rubber released). 


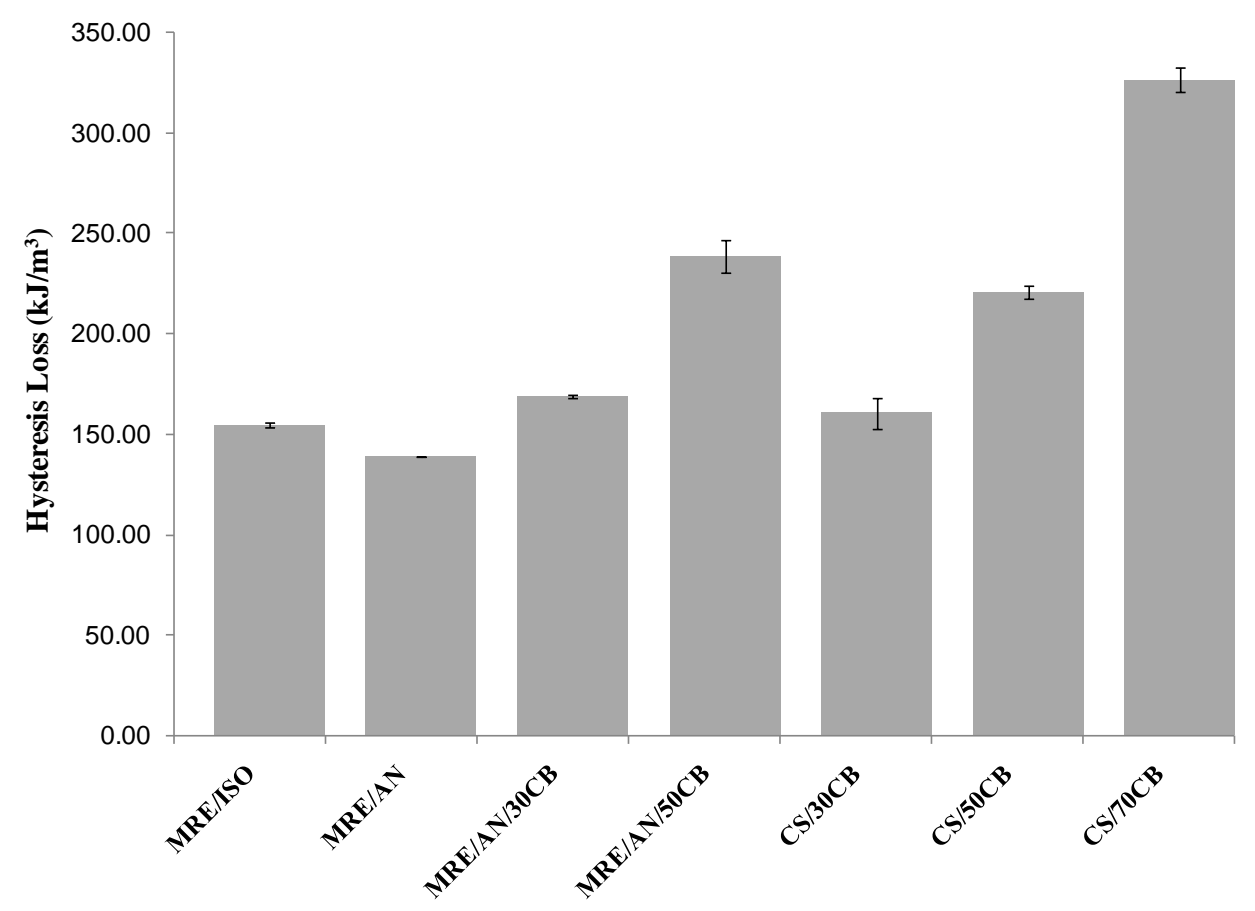

Figure 9 Hysteresis loss for MREs and comparative samples.

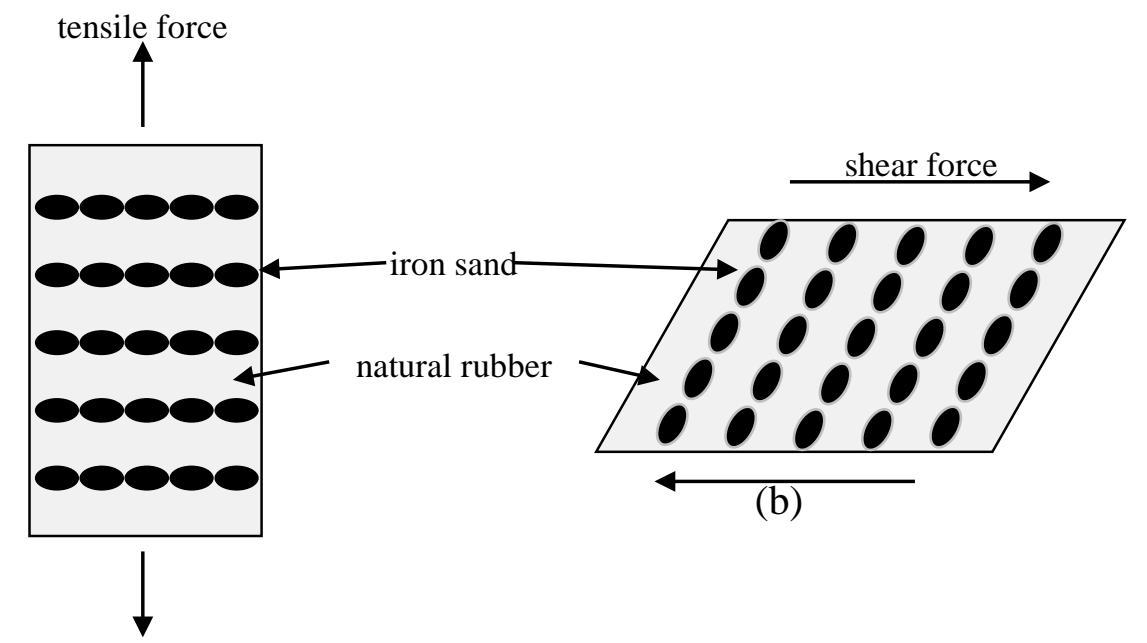

Figure 10 Comparison of influence of loading types on particle separation, (a) tensile mode, (b) shear mode. 


\subsection{CONCLUSION}

It was found that isotropic MREs had uniform iron sand particle distribution without obvious aggregation and alignment of magnetic particles occurred for anisotropic MREs as a consequence of curing the materials under an applied magnetic field at elevated temperature. For comparative samples, carbon black particles were generally evenly distributed in the rubber matrix with some aggregates, but none larger than $20 \mu \mathrm{m}$. SEM also revealed that addition of carbon black into anisotropic MREs constrained the movement of iron sand particles; chain-like columnar structures became shorter and less aligned. Energy absorption for comparative samples (CS/30CB, CS/50CB and CS/70CB) was generally found higher than MRE/ISO and MRE/AN over the range of frequency and strain amplitude explored, as well as in hysteresis testing and this was believed to be largely due the presence of carbon black in the formulation. Further assessment carried out on materials that were the same as MRE/AN except they had additions of 30 and 50 phr carbon black (MRE/AN/30CB and MRE/AN/50CB) gave generally higher energy absorption than comparative samples of the same carbon black contents (CS/30CB and CS/50CB), supporting the use of iron sand to improve damping through interfacial damping between the particle and the rubber matrix and magnetic interactions (magnetomechanical and inter-particle interaction). However, trends for energy absorption at around $\mathrm{T}_{\mathrm{g}}$ were found to reverse which can be explained by the segmental motion of rubber chains being by far the most significant influence on energy absorption at this temperature as supported by literature and so care should be taken when using the materials at such temperature although this is likely to be away from the service temperature for these materials.

\subsection{ACKNOWLEDGEMENTS}

The authors would like to thank for the support from the Polymer and Composite Research Group of the University of Waikato. 


\subsection{REFERENCES}

[1] Sun Y, Zhou X, Liu Y, Zhao G, Jiang Y. Effect of magnetic nanoparticles on the properties of magnetic rubber. Materials Research Bulletin. 2009;45(7):878-81.

[2] Makled MH, Matsui T, Tsuda H, Mabuchi H, El-Mansy MK, Morii K. Magnetic and dynamic mechanical properties of barium ferrite natural rubber composites. Journal of Materials Processing Technology. 2005;160(2):229-33.

[3] Dobrzanski LA, Tomiczek A, Tomiczek B, Slawska A, Iesenchuk O. Polymer matrix composite materials reinforced by Tb0.3Dy0.7Fe1.9 magnetostrictive particles. Journal of Achievements in Materials and Manufacturing Engineering. 2009;37(1):16-23.

[4] Chen L, Gong XL, Li WH. Effect of carbon black on the mechanical performances of magnetorheological elastomers. Polymer Testing. 2008;27(3):340-5.

[5] Jerzy K, Michal K, Daniel L. Magnetomechanical properties of anisotropic and isotropic magnetorheological composites with thermoplastic elastomer matrices. Smart Mater Struct. 2011;20(8):12.

[6] Chokkalingam R, Rajasabai Senthur P, Mahendran M. Magnetomechanical behavior of Fe/PU magnetorheological elastomers. Journal of Composite Materials. 2010;45(15):154552.

[7] Fuchs A, Zhang Q, Elkins J, Gordaninejad F, Evrensel C. Development and characterization of magnetorheological elastomers. Journal of Applied Polymer Science. 2007;105(5):2497-508.

[8] Ginder J. Magnetorheological elastomers: properties and applications. Proc SPIE. 1999;3675(1):131.

[9] Lerner AA, Cunefare KA. Performance of MRE-based Vibration Absorbers. Journal of Intelligent Material Systems and Structures. 2008;19(5):551-63.

[10] Sun TL, Gong XL, Jiang WQ, Li JF, Xu ZB, Li WH. Study on the damping properties of magnetorheological elastomers based on cis-polybutadiene rubber. Polymer Testing. 2008;27(4):520-6.

[11] Wang Y, Hu Y, Deng H, Gong X, Zhang P, Jiang W, et al. Magnetorheological elastomers based on isobutylene-isoprene rubber. Polymer Engineering \& Science. 2006;46(3):264-8.

[12] Boczkowska A, Awietjan SF, Pietrzko SA, J. KOK. Mechanical properties of magnetorheological elastomers under shear deformation. Composites Part B: Engineering. 2012;43(2):636-40.

[13] Deng HX, Gong XL. Application of magnetorheological elastomer to vibration absorber. Communications in Nonlinear Science and Numerical Simulation. 2008;13(9):1938-47.

[14] Dyke SJ, Spencer JR, Sain MK, Carlson JD. Modeling and control of magnetorheological dampers for seismic response reduction. Smart Materials and Structures. 1996;5(5):565-75.

[15] Pickering KL, Raa Khimi S, Ilanko S. The effect of silane coupling agent on iron sand for use in magnetorheological elastomers part 1: Surface chemical modification and characterization. Composites Part A: Applied Science and Manufacturing.

[16] Xiuying Q, Xiushou L, Weihua L, Jun C, Xinglong G, Tao Y, et al. Microstructure and magnetorheological properties of the thermoplastic magnetorheological elastomer composites containing modified carbonyl iron particles and poly(styrene- b -ethyleneethylenepropylene- b -styrene) matrix. Smart Materials and Structures. 2012;21(11):115028. 
[17] Wang YL, Hu YA, Chen L, Gong XL, Jiang WQ, Zhang PQ, et al. Effects of rubber/magnetic particle interactions on the performance of magnetorheological elastomers. Polymer Testing. 2006;25(2):262-7.

[18] Lakes RS. High Damping Composite Materials: Effect of Structural Hierarchy. Journal of Composite Materials. 2001;36(3):287-97.

[19] Raa Khimi S, Pickering KL. A new method to predict optimum cure time of rubber compound using dynamic mechanical analysis. Journal of Applied Polymer Science. 2013;131(6):n/a-n/a.

[20] Kasgoz A, Akin D, Durmus A. Rheological and electrical properties of carbon black and carbon fiber filled cyclic olefin copolymer composites. Composites Part B: Engineering. 2014;62(0):113-20.

[21] Kallio M. The elastic and damping properties of magnetorheological elastomers. 1 ed. Finland: VTT Technical Research Centre of Finland; 2005.

[22] Wang MJ. Effect of Polymer-Filler and Filler-Filler Interactions on Dynamic Properties of Filled Vulcanizates. Rubber Chemistry and Technology. 1998;71(3):520-89.

[23] Kraus G. Reinforcement of elastomers by carbon black. Fortschritte der Hochpolymeren-Forschung. Berlin: Springer Berlin Heidelberg; 1971. p. 155-237.

[24] Jovanovic V, Samarzija-Jovanovic S, Budinski-Simendic J, Markovic G, MarinovicCincovic M. Composites based on carbon black reinforced NBR/EPDM rubber blends. Composites Part B: Engineering. 2013;45(1):333-40.

[25] Wang M-J. The role of filler networking in dynamic properties of filled rubber. Rubber Chemistry and Technology. 1999;72(2):430-48.

[26] Rendek M, Lion A. Amplitude dependence of filler-reinforced rubber: Experiments, constitutive modelling and FEM Implementation. International Journal of Solids and Structures. 2010;47(21):2918-36.

[27] Li Y, Han B, Liu L, Zhang F, Zhang L, Wen S, et al. Surface modification of silica by two-step method and properties of solution styrene butadiene rubber (SSBR) nanocomposites filled with modified silica. Composites Science and Technology. 2013;88(0):69-75.

[28] Raa Khimi S, Pickering KL, Mace BR. Dynamic properties of magnetorheological elastomers based on iron sand and natural rubber. Journal of Applied Polymer Science.

[29] Kucherskii AM. Hysteresis losses in carbon-black-filled rubbers under small and large elongations. Polymer Testing. 2005;24(6):733-8.

[30] Meier JG, Kluppel M. Carbon black networking in elastomers monitored by dynamic mechanical and dielectric spectroscopy. Macromolecular materials and engineering. 2008;293(1):12-38. 